NBER WORKING PAPER SERIES

\title{
METHODOLOGICAL ISSUES IN THE EVALUATION OF PARENTAL INVOLVEMENT LAWS: EVIDENCE FROM TEXAS
}

\author{
Silvie Colman \\ Theodore J. Joyce \\ Robert Kaestner \\ Working Paper 12608 \\ http://www.nber.org/papers/w12608
NATIONAL BUREAU OF ECONOMIC RESEARCH
1050 Massachusetts Avenue
Cambridge, MA 02138
October 2006

This research is supported by a grant from the National Institute of Child Health and Human Development (NICHD) to the National Bureau of Economic Research (R03 HD49359-01). Officials from NICHD had no role in the study. Human Subject approval was granted by the Institutional Review Board of the Texas Department of State Health Services on October 27, 2004 (IRB\# 04-051). We thank Stanley Henshaw for information on abortions to teens from Texas in New Mexico. We also thank seminar participants at the National Bureau of Economic Research Health Economics Conference, Johns Hopkins University, Baruch College School of Public Affairs, Rice University and the University of Houston. The views expressed herein are those of the author(s) and do not necessarily reflect the views of the National Bureau of Economic Research.

(C) 2006 by Silvie Colman, Theodore J. Joyce, and Robert Kaestner. All rights reserved. Short sections of text, not to exceed two paragraphs, may be quoted without explicit permission provided that full credit, including $\odot$ notice, is given to the source. 
Methodological Issues in the Evaluation of Parental Involvement Laws: Evidence from Texas

Silvie Colman, Theodore J. Joyce, and Robert Kaestner

NBER Working Paper No. 12608

October 2006

JEL No. J13,J18

\begin{abstract}
$\underline{\text { ABSTRACT }}$
The number of states that require parental involvement in a minor's decision to terminate a pregnancy has more than doubled since 1988. Congress is currently considering legislation that would further limit access to abortion for minors who reside in states that enforce parental involvement laws. So far, the academic literature has not reached a consensus as to the impact of such abortion restrictions, mainly due to methodological limitations caused by the inability to measure cross-state travel and misclassification of exposure. Using detailed data on abortions and births from Texas, we demonstrate that these limitations led researchers to overestimate the decline in minors' abortion rate, underestimate the increase in their birth rate, and to miss an important behavioral response to the law, which is the tendency to delay the abortion among a group of older minors. Correction of these methodological problems is important given the controversy surrounding abortion and the need of voters and policymakers to accurately assess the likely impact of these laws.
\end{abstract}

Silvie Colman

Graduate Center

The City Univeristy of New York

365 Fifth Avenue

New York, NY 10016-4309

scolman@gc.cuny.edu

Theodore J. Joyce

NBER

365 Fifth Avenue, 5th Floor

New York, NY 10016-4309

Ted_Joyce@baruch.cuny.edu
Robert Kaestner

Institute of Government and Public Affairs

University of Illinois at Chicago

815 West Van Buren Street, Suite 525

Chicago, IL 60607

and NBER

kaestner@uic.edu 


\section{Introduction}

Parental involvement laws require that an abortion provider notify a parent(s) of a minor's request for an abortion, or that the parent(s) provide written consent, before a procedure can be performed. In 1988, only 13 states had such laws, but currently, thirty-five states enforce parental involvement laws. ${ }^{1}$ Residents of California and Oregon will vote this November on whether to make parental notification requirement for minors seeking an abortion state law. Further, legislation in both the U.S. House and Senate would extend enforcement of the parental involvement law in the minor's state of residence to any state in which she sought an abortion. ${ }^{2}$ Such legislation could substantially increase the effect of a parental notification law in California and Oregon, since it would prevent minors from traveling to Nevada and Washington in order to avoid compliance.

A major argument by proponents of such laws is that they reduce teen abortions and lower teen pregnancy rates. ${ }^{3}$ This inference is based on studies that report a fall in abortions among minors in response to a parental involvement law unaccompanied by a rise in births. Many voters and policymakers would view favorably such a decline in teen pregnancies. If, however, the decline in teen pregnancies is spurious, and if in fact birth rates rose after a parental involvement law, then the subsequent rise in unintended childbearing by minors would likely dampen enthusiasm for such laws.

\footnotetext{
${ }^{1}$ NARAL (2006)

${ }^{2}$ The Senate has recently passed the Child Custody Protection Act and the House of Representatives passed a similar measure earlier, called the Child Interstate Abortion Notification Act (CIANA).

${ }^{3}$ Advocates of parental involvement laws in California are seeking to instate a parental notification statute through a ballot initiative in November of 2006. The website in support of the initiative cites as "fact" that parental involvement laws reduce "the number of abortions on teens by 15 percent while also reducing the overall teen pregnancy rate.” http://www.parentsright2know.org/images/Ca.needs2.pdf . See also http://www.ParentsRight2Know.org/
} 
The academic literature on the impact of parental involvement laws has not reached a consensus. Some studies suggest that parental involvement laws lower abortion rates among minors, but have little effect on birth rates (Rogers et al. 1991; Ohsfeldt and Gohmann 1994; Haas-Wilson 1996; Levine 2003). Other studies suggest that the observed decline in abortions is spurious, since abortions to minors obtained outside their state of residence are often not recorded (Cartoff and Klerman 1986; Henshaw 1995; Joyce and Kaestner 1996; Ellertson 1997). The conflicting findings reflect the difficulty of evaluating the impact of parental involvement laws on reproductive behavior. The canonical research design is a pre-post analysis with a comparison group. Changes in abortion and/or birth rates among minors are compared to changes among older teens. This seemingly straightforward test, however, is fraught with pitfalls that have not been fully appreciated by researchers, policy makers and advocates. In this study we extend our previous analysis of Texas's parental notification law to illustrate key limitations in previous work and demonstrate that correction of the methodological problems has significant implications for policy. First, we show that large differences in the abortion and birth rates between minors and older teens make inferences as to the effect of the law sensitive to how abortions and births are measured, if we employ the common strategy of using changes in reproductive outcomes among older teens as the counterfactual for minors. Second, we demonstrate that the estimated impact of the law on birth rates changes significantly depending on whether exposure to the law is determined based on age at the time of conception or age at the time of delivery. Third, we provide evidence that a substantial number of 17 -yearolds delay their abortion until they are 18 in order to get around the parental notification requirement. As a result, the law induces a rise in abortions among 18-year-olds and a fall in abortions among 17-year-olds, and estimates based on age at the time of abortion will overstate 
the decline in abortions among minors. Finally, we show that even if resident teens don't leave the state to obtain an abortion, fewer non-residents may come into the state for an abortion. Since all abortion data are collected by state of occurrence, a decline in minors’ abortions associated with the law may be overstated if non-resident abortions are included in the analyses. We conclude that differences in how exposure to the law is determined combined with seemingly subtle behavioral responses can have a major impact on the estimated effect of parental involvement laws on the abortion, birth and pregnancy rates of minors.

\section{Empirical Issues Affecting Previous Studies}

Data Limitations

The literature on parental involvement laws divides broadly into two types of studies: analyses based on state aggregate data and single or multiple-state studies that use individuallevel data from state health departments. Studies based on state aggregates use data from either the Centers for Disease Control and Prevention (CDC) or the Alan Guttmacher Institute (AGI). The CDC collects data from the state health departments in aggregate form. Data are available annually by state of occurrence and one other characteristic such as age or race, but not both. The Alan Guttmacher Institute surveys abortion providers periodically as to the total number of abortions performed in a specific year and makes available the total number of abortions performed in a state. The AGI estimates are widely considered the most accurate, but they provide no information on the characteristics of women that have an abortion. (Jones and Forrest 1992). Thus, neither the CDC nor the AGI aggregate data make it possible to analyze the effect of parental involvement laws by race or any other characteristics. 
The advantage of studies based on aggregate data is that most states are represented. This permits analyses based on pooled time-series cross-sections with state fixed effects (Ohsfeldt and Gohmann 1994; Haas-Wilson 1996; Levine 2003). On the other hand, studies using individual level data from one or several states allow for a more refined research design. For instance, researchers can stratify analyses by age, race, state of residence and the month of the abortion and thereby define those exposed and unexposed to the law with greater precision (Cartoff and Klerman 1986; Joyce and Kaestner 1996; Henshaw 1995; Ellertson 1997).

State of Residence vs. State of Occurrence

It has long been recognized that some minors, primarily older ones, who reside in a state that enforces a parental involvement statute, will seek an abortion in a nearby state without such requirement (Cartoff and Klerman 1986; Henshaw 1995; Joyce and Kaestner 1996; Ellertson 1997). In fact, the goal of the current legislation being considered by Congress is to limit such non-compliance. However, it is often not appreciated that minors for whom the nearest abortion provider is out-of-state may stop coming to that provider after the introduction of a parental involvement statute in the provider's state. Thus, if analyses are based on the number of abortions that were performed within a state, then part of the observed decline in abortions to minors associated with the law will be spurious (Cartoff and Klerman 1986; Henshaw 1995; Joyce and Kaestner 1996; Ellertson 1997).

The CDC and AGI aggregate abortion data are reported by state of occurrence and are not well suited for the evaluation of parental involvement laws because they will tend to overestimate the effect of the law. In fact, evidence from analyses that use state-level data suggests that effects are greater when based on abortions reported by state of occurrence (Haas- 
Wilson 1996) and less when based on abortions by state of residence (Ohsfeldt and Gohmann 1994; Levine 2003). However, it is uncertain that the latter studies capture the abortions obtained by minors out of state accurately. They employ the Alan Guttmacher Institute's estimates of abortion by age and state of residence that are produced by incorporating migration rates of all women provided by the CDC. These estimates do not account for the possibility of higher migration rates for minors due to parental involvement laws. Consequently, AGI researchers warn against the use of these data for the evaluation of parental involvement laws. ${ }^{4}$ In some studies that employ individual level data from state health departments, researchers have secured some information on abortions to minors performed outside their state of residence (Cartoff and Klerman 1986; Joyce and Kaestner 1996; Henshaw 1995; Ellertson 1997). The general finding from these studies is that abortions by state of occurrence fall significantly, but the decline by state of residence is significantly less.

Age at Time of Abortion (Birth) vs. Age at Conception

Given the limitations with reported abortions, many researchers use changes in births to minors to corroborate changes in abortions associated with parental involvement laws. A decline in abortions to minors after enforcement of a parental involvement law will result in a rise in births unless minors make a greater effort to avoid pregnancy or abstain from sex altogether in response to the more restrictive environment. Yet, even when abortions and births are counted accurately, inference as to the effect of the law is sensitive to the way exposure to the law is determined and how minors respond with respect to the timing of the abortion.

\footnotetext{
${ }^{4}$ Stanley Henshaw, who directed the AGI abortion survey for many years, writes,... "Thus, the estimated abortion and pregnancy rates should not be used to assess the impact of parental involvement laws on minors' abortion and pregnancy rates” (Henshaw, 1997, p. 116).
} 
In all previous studies but one, researchers have determined exposure to the law based on a teen's age at the time of the abortion or birth. However, three-fourths of all minors who conceive as 17-year-olds, give birth when they are 18 years of age. Thus, a pregnant 17-year old who carries to term because of a parental involvement law, will mostly likely give birth as an 18year old. Since the age of the mother is measured at the time of delivery and not at the point of conception, births to 18-year-olds who may have been affected by the law during pregnancy will not be counted if comparisons are between 17-year-olds in different states or will be included among the controls if changes among 18-year-olds within the state serve as the counterfactual. This form of misclassification bias drives estimates of the law's impact on birth rates towards the null, and may even lead to the erroneous inference that birth rates have declined or remained unchanged in response to the law (Rogers et al. 1991; Oshfeldt and Gohmann 1994; Ellertson 1997; Joyce and Kaestner 1996; Kane and Staiger 1996; Levine 2003).

The way exposure to the law is determined affects the inferences as to the effect of the law on minors' abortion rate as well. A less obvious response by minors exposed to a parental involvement statute is to delay the abortion until they turn 18. A recent analysis showed that for minors ages 17.5 to 17.74 at the time of conception, the odds of a second trimester abortion increased 35 percent after the introduction of a parental notification law in Texas (Joyce, Kaestner, and Colman 2006). This suggests that many minors, for whom delaying the abortion until after their $18^{\text {th }}$ birthday is feasible, will do so. Some of them are willing to wait even if it leads to a more risky second-trimester abortion. Such behavior causes a decline in abortions among older 17-year-olds and a rise in abortions among 18-year-olds and leads researchers to overestimate the impact of the law on the abortion rate of minors if exposure to the law is determined based on age at the time of abortion. 
The Appropriate Counterfactual

A common research design is to use changes in birth and abortion rates of older teens ages 18-19 as the counterfactual for minors ages 15-17 (Rogers et al. 1991; Oshfeldt and Gohmann 1994; Ellertson 1997; Joyce and Kaestner 1996; Haas-Wilson 1996; Kane and Staiger 1996). However, the abortion and birth rates of older teens are several times greater than that of minors, which raises questions as to the appropriateness of the comparison group (Meyer 1995). Large differences in the level of birth and abortion rates between minors and older teens suggest large differences in sexual activity, contraceptive use, previous pregnancy experience, schooling and labor market participation, all of which may affect trends in reproductive outcomes over time.

The large difference in the birth rate between minors and older teens can make the relative trends between the two age groups sensitive to measurement issues. In Figures 1a and 1b we show the birth rates of minors (15-17) and older teens (18-19) in the U.S. for the period 1992 to 2002. ${ }^{5}$ In Figure 1a, birth rates (births/population) are in levels and Figure 1b we present them transformed into natural logarithms. Fitted linear trend lines and their equations are added to each. As shown in Figure 1a, the birth rate of older teens is almost three times greater than that of minors. The annual decline among older teens, 2.01 births per 1000, is greater than the annual decline among minors of 1.57 births per 1000. So a comparison of year-to-year changes in births, such as one would do in evaluating the effect of a parental involvement law, would indicate that births declined more among older teens than minors. In contrast, when measured in logarithms, the annual decline in the birth rate of minors is more than double the decline of older

\footnotetext{
${ }^{5}$ Teen birth rates for the U.S. were taken from the National Vital Statistics Reports (see Martin et al. 2005).
} 
teens $(-0.051$ vs. -0.024 , Figure $1 \mathrm{~b})$, which would lead to the opposite inference in an evaluation of a parental involvement law.

The divergence in both the levels and trend of births between older teens and minors has important implications for the standard pre-post design with a comparison group, as demonstrated by this example. Because of the large difference in abortion and birth rates between minors and older teens, most researchers use relative changes (i.e., changes in logarithms) when analyzing effects of parental involvement laws. However, the sensitivity of inferences to measurement undermines the internal validity of the research design, as there is no a priori reason to favor one form of measurement over another. One solution is to use changes in birth or abortion rates of minors in states without a law as a counterfactual. However, differences between states with respect to the quality of data on abortions, the availability of abortion services, employment opportunities, welfare policies, demographic differences introduces other potential sources of confounding.

\section{Texas's Parental Notification Law}

In a recent analysis, we compared changes in birth and abortion rates among minors and older teens in Texas before and after enforcement of its parental notification law in January, 2000 (Joyce, Kaestner and Colman 2006). An innovation of the study was that we had information on teen's age at the time of conception and thus were able to identify exposure to the law more accurately. Furthermore, knowledge of the exact age at the time of conception enabled us to stratify the analysis by age in months, and thus narrow the age difference between the exposed and the comparison group. In Joyce et al. (2006) we found a reduction in the abortion rate of minors (ages 15, 16 and 17) relative to 18-year-olds after the law, but no change in 
relative birth rates. However, when we restricted the analysis to teens closer in age, we found that the birth rate of 17.5-17.74 year-olds increased relative to 18.0-18.24 year-olds after the law.

In this study, we extend our previous analysis in two primary ways. We provide difference-in-differences estimates of the effect of Texas' parental notification law on abortion and birth rates illustrating how the use of relative vs. absolute changes affects the evaluation of parental involvement laws. These estimates are initially obtained using age at the time of the abortions or birth, and then using age at the time of conception. The purpose of this is to demonstrate the magnitude of the bias and its significance for inference if exposure to the law is not identified appropriately.

Next, we use the difference-in-differences estimator to evaluate the impact of the parental notification law on the probability of abortion, given that a minor is pregnant. The regression framework allows us to control for characteristics such as race/ethnicity, marital status and previous pregnancies, and increases the statistical power in separate analysis by race. We also test whether the law's impact is changing over time. Finally, we demonstrate the number of abortions that were performed in Texas to non-residents by age before and after the implementation of Texas's parental notification law.

\section{Data}

We obtained individual birth certificates for the years 1992 to 2003 and abortion certificates from the period 1997 to 2003 from the Texas Department of State Health Services (DSHS). Data on abortions from Texas are unique along several dimensions. First, the abortion certificates include the patient's exact date of birth (in month/day/year format) and the exact date of the abortion. This information, combined with a clinical estimate of gestation, makes it 
possible to estimate the date of conception as well as age at conception, which allows us to identify the exposed and unexposed groups relatively precisely. Similarly, the birth certificates contain information on the mothers' date of birth as well as the date of delivery. Thus, we were able to measure a teen's age at the time of conception as well as at the time of the abortion or birth. Second, Texas is the most populous state in the country after California. The large census allowed us to stratify the analysis by race/ethnicity as well as by single year of age, and in some analyses, by age in months. Third, all states that border Texas with the exception of New Mexico, enforce parental involvement laws and the border between Texas and New Mexico is relatively unpopulated except for the El Paso area. Consequently few minors in Texas leave the state for an abortion, which mitigates the problem of not having information on minors that obtain their abortion out of state, a major limitation in previous analyses. ${ }^{6}$

The disadvantage of using the Texas data is that we cannot obtain comparable information on abortions from nearby states and must construct comparison groups from within Texas. None of the states that border Texas have comparative data. In Louisiana and New Mexico, statutory restrictions limit (or prohibit) the release of induced terminations at the individual level. Oklahoma did not collect data on induced terminations until 2000. Arkansas makes data available to researchers, but the abortion certificate does not report the patient's exact date of birth. Another limitation of the data from Texas abortion certificates is that reporting of date of birth is incomplete for the years 1997 and 1998. However, reporting has improved over time. For instance, 3419 (24.1 percent) of induced termination certificates lacked the patient's exact date of birth in 1997, 1278 (9.9 percent) in 1998, 389 (3.0 percent) in 1999, 44 (0.4 percent) in 2000, 911 (8.5 percent) in 2001, 2 (0.02 percent) in 2002 and 2 (0.02 percent) in

\footnotetext{
${ }^{6}$ See Joyce, Kaestner, and Colman (2006) for an estimated number of Texas teens that go to surrounding states for an abortion.
} 
2003. In contrast, the mother's date of birth is well recorded on birth certificates: less than one percent lacked this information each year. We excluded cases in which data were missing on the exact date of birth. To limit the possibility of bias associated with these exclusions, we limit most analyses to one year before and one year after the law, a time period during which there were relatively few missing data.

\section{Results}

Changes in Levels vs. Changes in Logarithms

In Table 1 we display abortion, birth and pregnancy rates of minors and older teens the year before and one year after the enforcement of Texas's parental notification law. The rates in Table 1 are constructed based on age at the time of abortion or birth, in order to produce estimates comparable to previous studies. Consider abortions first. The abortion rate of minors ages 15-17 fell from 11.4 per thousand in 1999 to 9.0 in 2000, a 23 percent reduction as measured by the difference in the natural logarithm of the rates (Table 1, Panel A, column 4). The abortion rate of older teens ages 18-19 fell only 5 percent during the same period, from 29.5 to 28.1. If we use the change among older teens as an estimate of the change that would have been observed among minors in absence of the law, then we obtain a decline associated with the law of 18 percent based on the difference-in-differences (DD) in logs (Table 1, Panel A, column 6; $\mathrm{p}<0.01$ ). The same comparison of births indicates that the birth rate of minors fell by 2.3 per thousand or 6 percent in the year after the law and the birth rate of older teens fell by 2.0 per thousand or approximately 2 percent (Table 1, Panel B, columns 3 and 4). Thus the estimated reduction in the birth rate of minors associated with the law is 4 percent when measured in 
relative terms (Table 1 , Panel $\mathrm{B}$, column 6; $<<0.01$ ), but no statistically significant change is observed when measured in levels (Table 1, Panel B, column 5).

The sensitivity of the DD estimates to whether changes are measured in levels or logs reflects the large differences in pre-law outcomes between minors and older teens. The abortion and birth rates of older teens is almost three times greater than that of minors. One alternative for researchers is to focus only on the estimates based on relative changes, but there is little justification for this. The large discrepancy in the level of birth and abortion rates between minors and older teens reflects differences in sexual activity, contraception, schooling and maturity. They also may reflect differences in trends as we showed in Figures 1a and 1b, which undermines the appropriateness of using older teens as a comparison group for minors (Meyer 1995).

In an effort to narrow the pre-law difference in abortion rates between those exposed and unexposed to the law, we limit the comparison to 17- and 18-year-olds in the next set of analyses. In Panels D and E of Table 1 we compare changes in abortion and birth rates before and after the law among this subgroup of teens. Again we measure age at the time of the abortion or birth. Inferences are now consistent regardless of whether we measure the change in levels or in logs. The DD estimates indicate that the abortion rate of 17-year-olds fell 3.5 per thousand or 26 percent more as compared to 18-year-olds (Table 1, Panel D, columns 5 and 6). Similarly, the DD estimate for birth rates indicate that the birth rate of 17-year-olds fell 4.6 per thousand or 7 percent more than that of 18-year-olds (Table 1, Panel E columns 5 and 6). 
Age at the Time of Abortion (Birth) vs. Age at Conception

An important limitation in previous studies of parental involvement laws has been the use of age at the time of the birth or abortion instead of age at conception. In Panels A and B of Table 2 we compare the abortion and birth rates between 17- and 18-year-olds based on age at the time of conception instead of age at the time of the abortion or birth. The relative decline in the abortion rate of 17-year-olds when age is measured at the time of conception is -1.91 per thousand, or -15 percent (Table 2, Panel A, columns 5 and 6), which is substantially less than the estimated reduction based on age at the time of the abortion ( -3.53 in levels and -0.26 in logs; Table 1). In the case of birth rates, differences are even more dramatic. When age is measured at the time of conception, the birth rate of 17 -year-olds rises by 2.76 births per thousand $(\mathrm{p}<0.1)$, or 2 percent (Table 2, Panel B, columns 5 and 6), while estimates based on age at the time of birth suggest a relative decline in the birth rate of 17-year-olds. Thus, when age is measured at the time of abortion or birth, Texas's parental notification law is associated with a large decline in the abortion rate accompanied by a reduction in the birth rate of 17 -year-olds. This is in stark contrast to the estimates based on age at conception, which suggest that Texas's parental notification law is associated with a smaller reduction in the abortion rate and an increase in the birth rate of 17-year-olds when measured in levels, and no change in their birth rate when measured in logs.

As a further indication of the importance of appropriately characterizing exposure to the law, we combine the results for abortion and birth rates in order to analyze the change in pregnancy rates by age at the time of abortion or birth versus age at conception. We define the pregnancy rate as the sum of birth and abortion rates. Again we focus on the comparison of 17 and 18-year-olds in Panel F of Table 1 and Panel C of Table 2. According to the results, when 
age is measured at the time of the birth or abortion, Texas's parental notification law is associated with an 11 percent decline in the pregnancy rate of 17-year-olds (Table 1, Panel F, column 6), a figure close to the decline claimed by advocates of parental involvement laws in California (see footnote 1). However, we uncover no change in the pregnancy rate of 17-yearolds when age is measured at the time of conception (Table 2, Panel C, column 6).

\section{Other Behavioral Responses}

As we noted above, minors may respond to a parental involvement law in ways that led researchers to overestimate the magnitude of the decline in abortions given how data are collected. This is precisely the result we showed earlier. The abortion rate of 17-year-olds declined 26 percent when measured by age at the time of the abortion, but only 15 percent when measured by age at conception. The discrepancy is due to the behavioral response of older minors to the parental involvement law. The data suggest that older minors delay their termination until they are 18 years of age, in order to avoid the parental notification requirement. This causes an increase in abortions to 18-year-olds and a decrease in abortions to 17-year-olds when age is measured at the time of the abortion, thus exaggerating the relative decline in the abortion rate of 17-year-olds. As evidence, we show the number of abortions by age in months for 17 and 18-year-olds, first by age at the time of abortion (Figure 2a) and separately by age at the time of conception (Figure 2b). We show two series: the number of abortions to teens who conceived in 2000, the year after the law, and the number of abortions conceived in 1999, the year prior to the law. ${ }^{7}$ In both figures, the number of abortions to all 18-year-olds is practically the same in 1999 and 2000. As expected from the results in Table 2, which show that Texas’s law reduced abortions among 17-year-olds compared to 18-year-olds, the number of abortions to

\footnotetext{
${ }^{7}$ Note, the pre-law year 1999 is the 12 months from August 1998-July 1999.
} 
17-year-olds is noticeably less in 2000 than in 1999 in both figures. But more importantly, in conception year 2000, there is a noticeable dip in the number of abortions among minors 17 years and 10 or 11 months of age and a jump in abortions to minors who were exactly 18 years of age at the time of abortion (Figure 2a). The difference in the number of abortions between minors 17 years and 11 months and teens 18 years and 0 months at termination is 173 in 2000 . In contrast, the number of abortions for conception year 1999 steadily increases with age. There were 264 abortions to minors who were 17 years and 11 months at the time of the termination and 305 abortions to teens who were exactly 18 years old, a change of only 41 abortions compared with 173 in 2000.

The estimated impact of the law is markedly different when age is measured at the time of conception, as demonstrated in Figure 2b. Unlike in Figure 2a, in Figure 2b we observe a continuous increase in the number of abortions with age for both 1999 and 2000. As in Figure 2a the number of abortions among 17-year-olds is noticeably less in 2000 as compared to 1999, however, there is no sharp discontinuity in the number of abortions in 2000 between minors who conceived a few months before their $18^{\text {th }}$ birthday and teens who conceived within a month of their $18^{\text {th }}$ birthday. Instead, the difference in the number of abortions between 1999 and 2000 gradually diminishes as age of conception approaches 18. The contrast between Figures 2a and 2b strongly suggest that there was a substantial number of minors who would have terminated the pregnancy while still 17 prior to the law, but who delayed the termination until they were 18 years of age one year after the law.

Figure 3 provides another way of presenting the impact of the law on the timing of abortion. The graph shows that of all abortions to minors who were 17 at the time of conception, the proportion that were performed at age 18 increased from 22 percent to 27 percent between 
1999 and 2000. As a comparison, Figure 3 also presents the proportion of abortions to 18-yearolds at the time of conception that were performed at age 19. This latter group of teens had no incentive to delay their abortion due to the law. As is evident, among teens that were 18 at the time of conception and obtained an abortion, there is little change in the proportion who aborted at age 19 .

Another behavioral response to parental involvement laws is that minors may leave their state of residence to obtain an abortion in a state without a parental involvement requirement (Cartoff and Klerman 1986; Henshaw 1995; Joyce and Kaestner 1996). Because abortion data are collected by state of occurrence, part of the observed decline in minors' abortion will be spurious if these out-of-state abortions are not counted. There is little evidence that minors in Texas sought abortions in other states (Joyce, Kaestner, and Colman 2006). The most apparent reason is that Louisiana, Arkansas and Oklahoma, three bordering states, already enforced or were in the process of implementing similar statutes. However, researchers may also overestimate the decline in abortions if non-resident minors stop coming into the state for an abortion. Table 3 shows the number of abortions to non-residents of Texas that were performed in Texas by age and state of residence, for the conception years 1999 and 2000. Most nonresident minors that obtained an abortion in Texas came from three bordering states, Louisiana, New Mexico and Oklahoma, and from the country of Mexico. The total number of non-resident abortions among 17-year-olds fell from 124 to 70 whereas abortions to non-resident 18-year-olds fell inconsequentially from 155 to 152 between 1999 and 2000. The difference in the decline in abortions between 17- and 18-year-olds is statistically significant $(\mathrm{p}<0.01)$. There was no meaningful change in the number of non-resident abortions among 15- and 16-year-olds (see footnote to Table 3). 
The results in Table 3 are consistent with findings from several other studies as to differences in behavior by age among minors. For instance, 17-year-olds are the least likely to communicate with their parents regarding an abortion or use of reproductive health services relative to younger minors, which suggests that they are most likely to be affected by a parental involvement statute (Henshaw and Kost 1992; Jones et al. 2005). The 41 percent decline in nonresident abortions to 17 -year-olds relative to 18 -year-olds indicates that parental notification laws are effective in discouraging non-resident older minors from obtaining an abortion in the state. Furthermore, the lack of minors from Mississippi, Arkansas, or Tennessee—states with parental involvement laws that are further away from Texas—suggests that a minor's travel across state lines is limited to nearby urban areas. In Texas, for example, over 95 percent $(\mathrm{n}=128)$ of minors 15 to 17 years of age from Oklahoma obtained their abortions in Dallas County in 1999 and 2000. Eighty-one percent (n=162) of minors from New Mexico went to El Paso county and 14 percent $(n=28)$ went to Lubbock county for an abortion. Sixty percent $(n=101)$ of minors from Mexico went to El Paso County and 24 percent $(n=41)$ went to Webb County in which the city of Laredo is located. The finding that most non-resident minors travel to the nearest urban center in Texas for an abortion likely explains why so few minors from Texas left the state for an abortion. Among the border states, New Mexico and Oklahoma did not enforce a parental involvement law in $2000 .^{8}$ But for minors in the population centers of Dallas, Houston, and San Antonio the nearest abortion provider in New Mexico is hundreds of miles away.

\footnotetext{
${ }^{8}$ The Oklahoma legislature introduced a bill limiting minors' access to abortion in 1999. As of 2002, the law was declared unenforceable (NARAL 2003).
} 


\section{Pregnancy Resolution}

In this section we analyze the effect of Texas's parental notification law on the conditional probability of an abortion given pregnancy. We define a pregnancy as a conception that results in a live birth or an induced abortion. An advantage of pregnancy resolution as an outcome is that we can conduct multivariate analyses at the individual level and test for differential effects by age, race and year of conception. ${ }^{9}$ The basic regression is as follows:

$$
P_{i t}=\alpha_{0}+\beta A_{i}+\alpha Y_{t}+\gamma\left(A_{i} * Y_{t}\right)+\mathbf{X} \boldsymbol{\pi}+e_{i t}
$$

where $\mathrm{P}_{\mathrm{it}}$ is the probability that teen $\mathrm{i}$ who conceived in year $\mathrm{t}$ aborts; $\mathrm{Y}_{\mathrm{t}}$ is a dichotomous indicator of the year after the law; $A_{i}$ is a dichotomous indicator for minors, more specifically of those age 17 at the time of conception; $A_{i}{ }^{*} Y_{t}$ is the interaction of year and age; $\mathbf{X}$ is a vector of characteristics that includes indicators for race/ethnicity, previous live births, previous induced abortions, marital status at the time of the birth or abortion and health service region of residence. ${ }^{10}$ We use a linear probability model which simplifies interpretation as well as the estimation of the standard errors given the extensive set of interactions that we include. ${ }^{11}$ Results from the estimation of the basic specification are shown in Table 4. The conditional probability of an abortion among 17- relative to 18-year-olds fell 2.2 percentage points in the first year after the law (Table 4, column 1). This represents a 13 percent decline given a mean conditional probability of abortion for 17-year-olds of 0.165 . Next, we tested whether the effect of the law

\footnotetext{
${ }^{9}$ A limitation of abortion conditional on pregnancy as an outcome is that it obscures the association between the law and probability of becoming pregnant. However, as we demonstrated in Table 2, Texas's parental notification law was not associated with a change in pregnancy rates, which suggests that most minors, in the short run at least, do not respond to the law until they become pregnant.

${ }^{10}$ Texas is divided into 11 health service regions. For a map go to: http://www.dshs.state.tx.us/regions/stregctymap.pdf.

${ }^{11}$ The mean of $P_{i t}$ is 0.165 and thus LPM and the logit give similar results. See Ai and Norton (2003) for an explanation of the standard errors of the marginal effects in the case of logit and probit.
} 
on the probability of aborting a pregnancy changed over time. ${ }^{12}$ We found a 1.9 percentage point decline in $2001(\mathrm{p}<0.01)$ and a 1.6 percentage point decline in $2002(\mathrm{p}<0.01)$ relative to 1999 but we cannot reject the null of no difference in the mean decline by year (Table 4, column 2). Since the estimates suggest no statistically significant difference in the effect of the law over time, in the next model we combine all three years (2000-2002) into one after period and test whether the effect of the law differs by race (Table 4, column 3). We show the difference-in-differences estimates by race/ethnicity as well as test whether the results differ by race and ethnicity. The probability of an abortion among white non-Hispanics who are 17 years of age at conception falls 2.3 percentage point in 2000-2002 relative to $1999(\mathrm{p}<0.01)$. We find no change in pregnancy resolution among black non-Hispanics and obtain a decline of 2.1 percentage points among Hispanics $(\mathrm{p}<0.01)$ associated with the law. The difference in the DD estimates between whites and blacks is statistically significant $(\mathrm{p}<0.10)$.

The racial differences in pregnancy resolution are consistent with racial and ethnic differences in communication between minors and parents about the use of reproductive health services (Jones et al. 2005; Reddy, Fleming and Swain 2002). In a recent survey of minors at family planning clinics, 53.1 percent of Hispanics, 58.1 of white non-Hispanics and 75.9 of black non-Hispanics reported that their parents knew of their use of the clinic's services (Jones et al. 2005). In an earlier study, researchers reported that parents of African-American girls were more likely to know that the minor sought an abortion than were the parents of white girls (Henshaw and Kost 1992). In other words, laws that mandate communication between parents and minors regarding the use of reproductive services should have less impact among black non-Hispanics as compared to white-non-Hispanics and Hispanics.

\footnotetext{
${ }^{12}$ For the conception year 2001, 640 (7.2\%) of abortion records with reported age at the time of abortion of 17-19 lacked mother's date of birth and thus were excluded from the analysis. The exclusion of these records may bias the estimated effect of the law for the year 2001. The bias will depend on the distribution of missing records by age.
} 


\section{Conclusions}

Voters in California and Oregon will decide this November whether to enforce a parental notification law for minors seeking an abortion. Advocates for such laws cite social science research that shows that parental involvement laws lower both abortions and pregnancies to minors. In this paper, we show that results from previous studies as to the likely impact of these laws are biased due to methodological limitations and therefore should be interpreted with caution. With unique data on abortions and births from Texas, we show that data limitations, questionable comparison groups and the difficulty in accurately measuring exposure to such laws can lead to erroneous inferences. We emphasize that correction of these methodological problems is important given the controversy surrounding abortion and the need of voters and policymakers to accurately assess the likely impact of such laws.

We have three main findings. First, we showed that due to large differences in the birth rates between 15-17 and 18-19 year-olds, the standard difference-in-differences estimates that are based on these two groups are sensitive to functional form. Consequently, we emphasized results obtained from the comparison of 17- and 18-year-olds in order to narrow the difference in the pre-law abortion and birth rate between the exposed and unexposed groups. Second, we demonstrated the importance of identifying those affected and unaffected by the law during pregnancy based on age at conception instead of age at the outcome of the pregnancy. We found that Texas’s parental notification law was associated with a fall in abortion rates but no change in pregnancy rates when exposure to the law is determined by age at conception, a finding contrary to a recent analysis of parental involvement laws in all 50 states (Levine 2003). Our study also suggests that some older minors delay their abortion until they are 18 years of age in response to the law. Prior research has been unable to account for such behavior and have likely 
overestimated the impact of parental involvement laws on minors' abortion rates. Finally, our results suggest that parental notification laws are effective in discouraging non-resident minors from obtaining an abortion in the state. This introduces an additional bias into the analyses if abortions are measured by state of occurrence, as is the case in previous studies that utilize the AGI estimates or the aggregate CDC data. In sum, Texas's parental notification law had a significant impact on the behavior of minors residing inside and outside the state. We would expect similar responses in California and Oregon if parental notification becomes law and access to out-of-state abortion providers that do not require parental notification is restricted by federal legislation. 


\section{References}

Ai, C., \& Norton, E. C. (2003). Interaction Terms in Logit and Probit Models. Economic Letters, 80(1), 123-129.

Cartoff, V., \& Klerman, L. (1986). Parental consent for abortion: Impact of the Massachusetts Law. American Journal of Public Health, 76(4), 397-400.

Ellertson, C. (1997). Mandatory parental involvement in minors' abortions: Effects of the laws in Minnesota, Missouri, and Indiana. American Journal of Public Health, 87(8), 367-1374.

Haas-Wilson, D. (1996). The impact of state abortion restrictions on minors' demand for abortions. Journal of Human Resources, 31(1), 140-158.

Henshaw, S., \& Kost, K. (1992). Parental involvement in minors' abortion decisions. Family Planning Perspectives, 24(5), 196-207.

Henshaw, S. (1995). The impact of requirements for parental consent on minors' abortions in Mississippi. Family Planning Perspectives, 27(3), 120-122.

Henshaw, S. (1997). Teenage abortion and pregnancy statistics by state. Family Planning Perspectives, 29(3), 115-122.

Jones, E. F., \& Forrest, J. D. (1992). Underreporting of abortion in surveys of U.S. women: 1976 to 1988. Demography, 29(1), 113-126.

Jones, R. K., Purcell, A., Singh, S., \& Finer, L. B. (2005). Adolescents’ reports of parental knowledge of adolescents' use of sexual health services and their reactions to mandated parental notification for prescription contraception. The Journal of the American Medical Association, 293(3), 340-348.

Joyce, T., \& Kaestner, R. (1996). State reproductive policies and adolescent pregnancy resolution: The case of parental involvement laws. Journal of Health Economics,15(5), 579-607.

Joyce, T., Kaestner, R., \& Colman, S. (2006). Changes in abortions and births and the Texas parental notification law. New England Journal of Medicine, 354(10), 1031-1038.

Kane, T., \& Staiger, D. (1996). Teen motherhood and abortion access. Quarterly Journal of Economics, 111(2), 467-506.

Levine, P. B. (2003). Parental involvement laws and fertility behavior. Journal of Health Economics, 22(5), 861-878. 
Martin, J. A., Hamilton, B. E., Sutton, P. D., Ventura, S. J., Menacker, F., \& Munson M. L. (2005, September 8). Births: Final data for 2003. National Vital Statistics Reports, Vol. 54 No 2, National Center for Health Statistics.

Meyer, B. D. (1995). Natural and quasi-experiments in economics. Journal of Business and Economic Statistics, 13(2), 151-161.

National Abortion and Reproductive Action Rights League / NARAL (2003). Who decides? A state-by-state review of abortion and reproductive rights. Fifteenth Edition Washington, DC: The NARAL Foundation.

National Abortion and Reproductive Action Rights League / NARAL (2006). Who decides? A state-by-state review of abortion and reproductive rights. Fifteenth Edition Washington, DC: The NARAL Foundation.

Ohsfeldt, R., \& Gohmann, S. (1994). Do parental involvement laws reduce adolescent abortion rates? Contemporary Policy Issues, 12(2), 65-76.

Reddy, D.M., Fleming, R., \& Swain, C. (2002). Effect of mandatory parental notification on adolescent girls' use of sexual health care services. The Journal of the American Medical Association, 288(6), 710-714.

Rogers, J., Boruch, R., Stoms, G., \& DeMoya, D. (1991). Impact of the Minnesota parental notification law on abortion and birth. American Journal of Public Health, 81(3), 294-298. 
Figure 1a. U.S. birth rates of minors and older teens with fitted linear trend lines

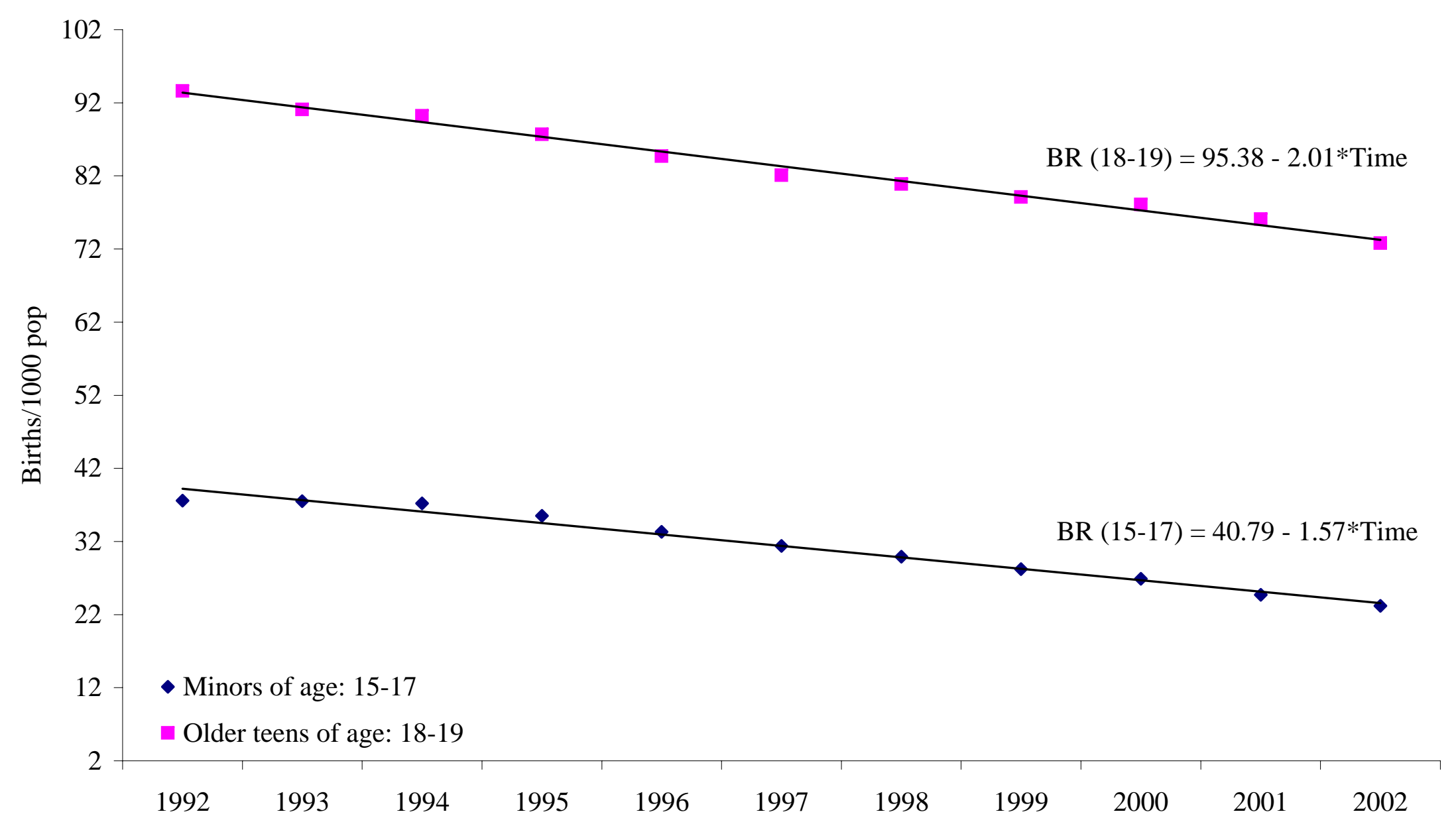

Notes: Birth rates by age group were obtained from the National Vital Statistics Reports, Vol. 54, No. 2 (see Martin et al. 2005). 
Figure 1b. U.S. birth rates of minors and older teens in logs with fitted linear trend lines

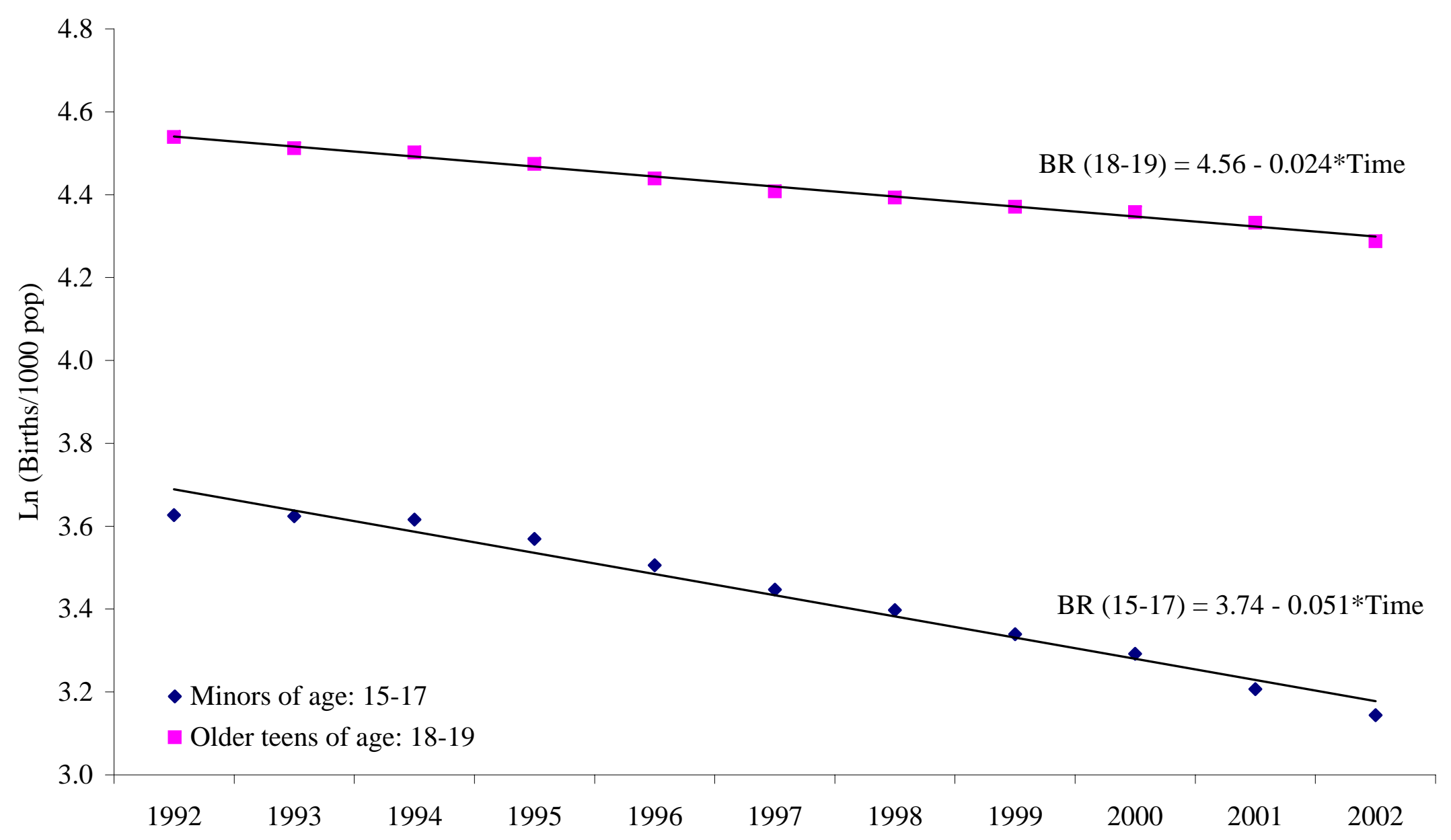

Notes: Birth rates by age group were obtained from the National Vital Statistics Reports, Vol. 54, No. 2 (see Martin et al. 2005). 
Figure 2a. Number of abortions to Texas residents by age in months at the time of abortion and year of conception

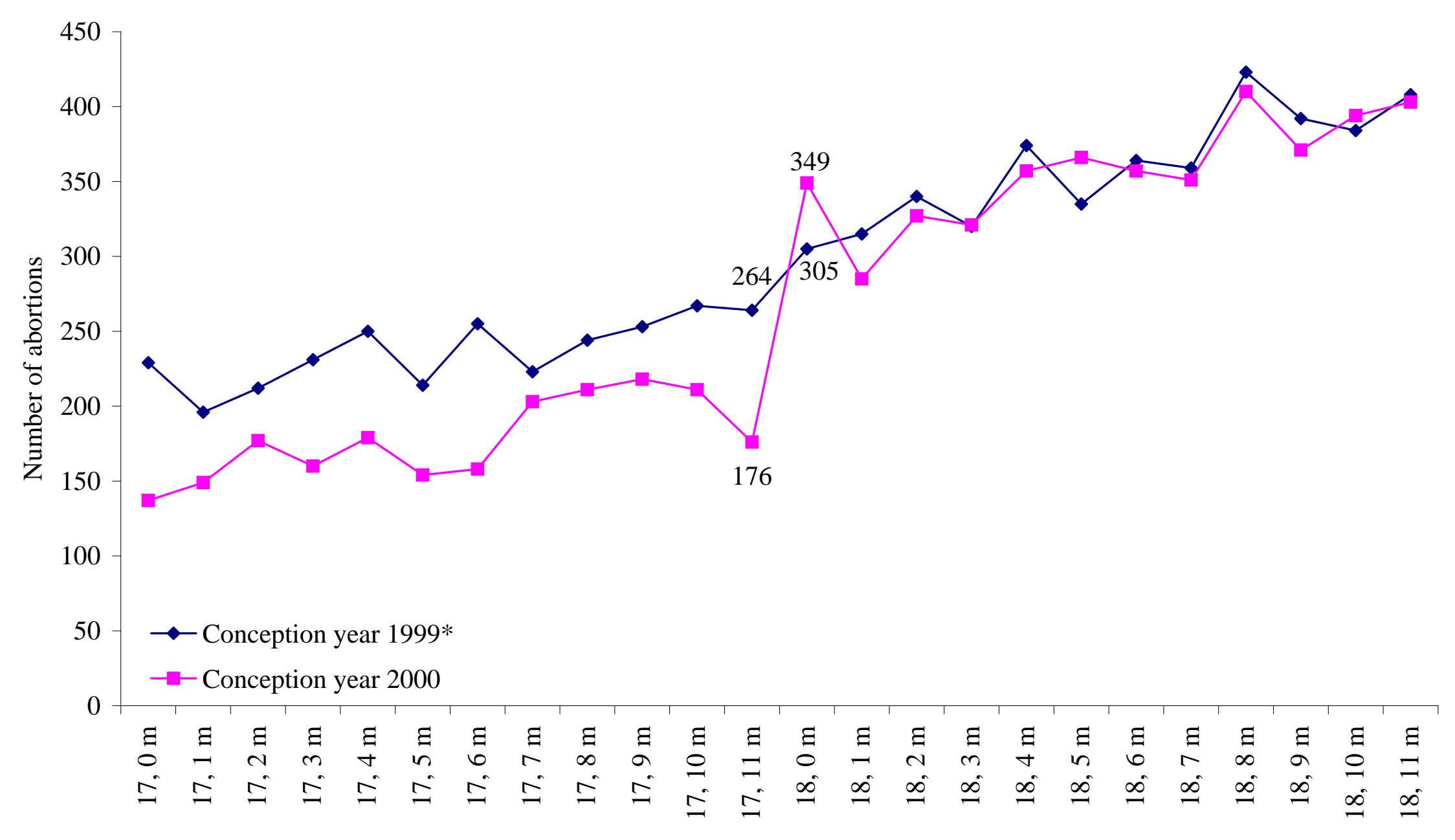

Age at time of abortion

*Refers to the period August 1, 1998 to July 31, 1999.

Source: Authors' tabulation of induced terminatin of pregnancy records from TDSHS. 
Figure $2 b$. Number of abortions to Texas residents by age in months at the time of conception and year of conception

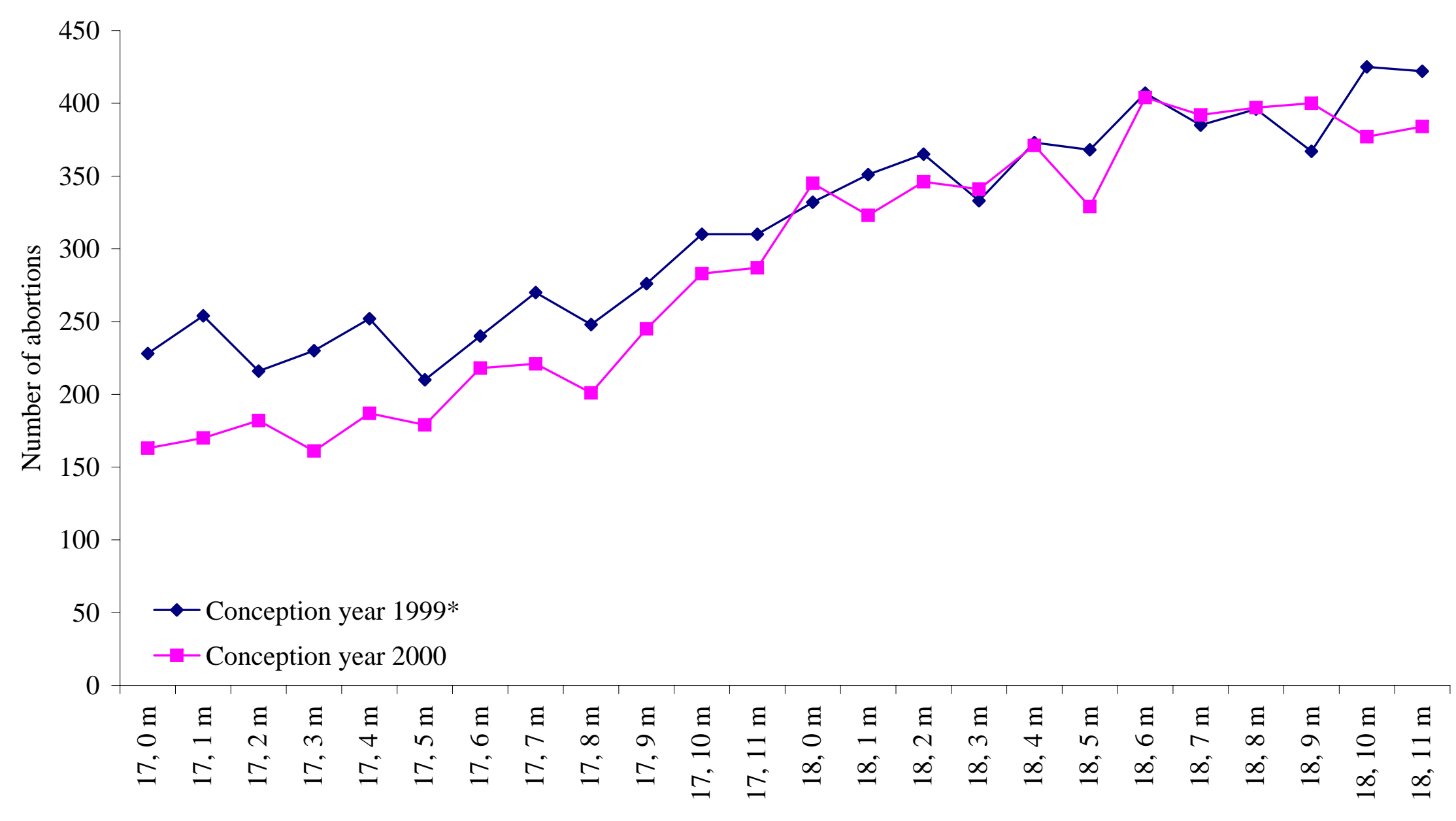

Age at time of conception

*Refers to the period August 1, 1998 to July 31, 1999.

Source: Authors' tabulation of induced terminatin of pregnancy records from TDSHS. 
Figure 3. The proportion of abortions that were obtained at age 18, of all abortions to minors who were 17 at the time of conception, as compared to the proportion of abortions that were obtained at age 19, of all abortions to teens who were 18 at the time of conception; Texas residents, conception years 1998-2002

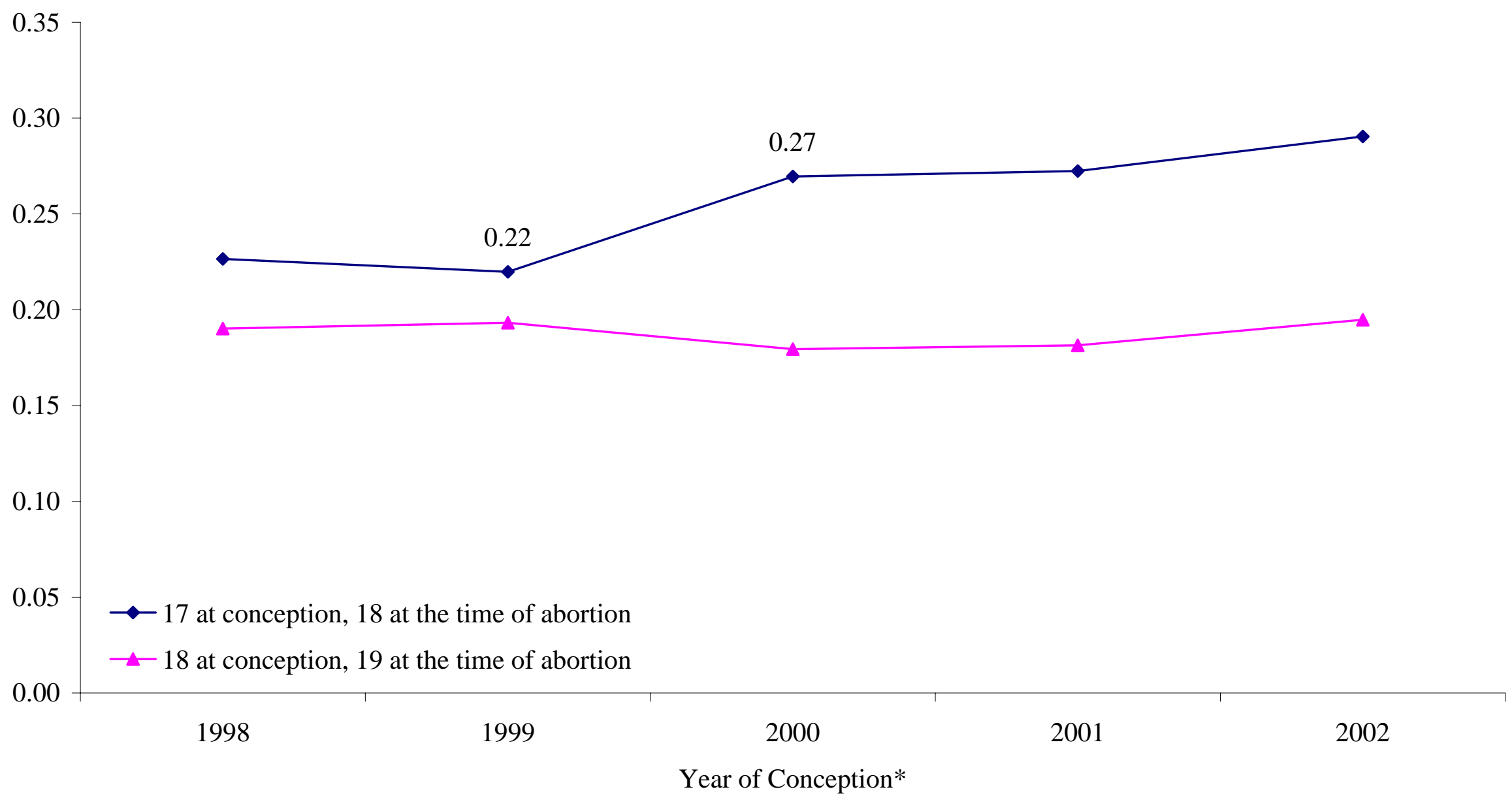

*1998 refers to the period August 1, 1997 to July 31, 1998; 1999 refers to the period August 1, 1998 to July 31, 1999. Source: Authors' tabulation of induced terminatin of pregnancy records from TDSHS. 
Table 1. Abortion, birth and pregnancy rates for minors 15-17 vs. teens 18-19 and for minors age 17 vs. teens age 18, by age at the time of pregnancy resolution and year of conception, Texas residents $^{\#}$

\begin{tabular}{cccccc}
\hline $1999^{+}$ & 2000 & Diff. & Log Diff. & DD & Log DD \\
\hline$(1)$ & $(2)$ & $(3)$ & $(4)$ & $(5)$ & $(6)$ \\
\hline
\end{tabular}

\section{Minors of Age 15-17 vs. Teens of Age 18-19:}

Panel A - Abortion Rate

$\begin{array}{lcccccc}15-17 & 11.4 & 9.0 & -2.4 & -0.23 & -0.88(0.47) & -0.18(0.03)^{* *} \\ 18-19 & 29.5 & 28.1 & -1.5 & -0.05 & & \end{array}$

Panel B - Birth Rate

$\begin{array}{ccccccc}15-17 & 41.1 & 38.8 & -2.3 & -0.06 & -0.28(0.88) & -0.04(0.01)^{* *} \\ 18-19 & 108.1 & 106.0 & -2.0 & -0.02 & & \end{array}$

Panel C - Pregnancy Rate

$\begin{array}{ccccccc}15-17 & 52.4 & 47.8 & -4.7 & -0.09 & -1.16(0.98) & -0.07(0.01)^{* *} \\ 18-19 & 137.6 & 134.1 & -3.5 & -0.03 & & \end{array}$

\section{Minors of Age 17 vs. Teens of Age 18:}

Panel D - Abortion Rate

$\begin{array}{lllllll}17 & 17.5 & 13.1 & -4.4 & -0.29 & -3.53(0.72)^{* *} & -0.26(0.04)^{* *} \\ 18 & 27.0 & 26.1 & -0.9 & -0.03 & & \end{array}$

Panel E - Birth Rate

\begin{tabular}{|c|c|c|c|c|c|c|}
\hline 17 & 66.7 & 62.0 & -4.7 & -0.07 & $-4.55(1.37)^{* *}$ & $-0.07(0.02)^{* *}$ \\
\hline 18 & 94.1 & 94.0 & -0.1 & 0.00 & & \\
\hline
\end{tabular}

Panel F - Pregnancy Rate

$\begin{array}{lcccccc}17 & 84.1 & 75.1 & -9.1 & -0.11 & -8.08(1.52)^{* *} & -0.11(0.02)^{* *} \\ 18 & 121.1 & 120.1 & -1.0 & -0.01 & & \end{array}$

\footnotetext{
"In columns (1) and (2), the rates are defined as the number of abortions (births) per 1000 age specific female population. Column (3) has the difference in the rates between 2000 and 1999, and column (4) contains the difference in the natural logarithm of the rates. Columns (5) and (6) have the difference-in-differences estimates in levels and logs respectively, and their standard errors. The standard errors are estimated by the delta method. (For a description of this method see the Supplementary Appendix to Joyce, Kaestner, and Colman (2006) available at http://content.nejm.org/cgi/data/354/10/1031/DC1/1).

${ }^{+}$Refers to the period from August 1, 1998 to July 31, 1999.

${ }^{* *}$ significant at $1 \%$; ${ }^{*}$ significant at $5 \%$
} 
Table 2. Abortion, birth and pregnancy rates for 17 and 18-year-olds by age at the time of conception and year of conception, Texas residents ${ }^{\#}$

$\begin{array}{llllll}1999 & 2000 & \text { Diff. } & \text { Log Diff. } & \text { DD } & \text { Log DD }\end{array}$

$\begin{array}{llllll}(1) & (2) & (3) & (4) & \text { (5) } & \text { (6) }\end{array}$

Panel A - Abortion Rate

$\begin{array}{lllllll}17 & 18.7 & 15.3 & -3.4 & -0.20 & -1.91(0.75)^{*} & -0.15(0.03)^{* *} \\ 18 & 28.3 & 26.9 & -1.5 & -0.05 & & \end{array}$

Panel B - Birth Rate

$\begin{array}{lcccccc}17 & 86.0 & 85.8 & -0.1 & 0.00 & 2.76(1.52) & 0.02(0.02) \\ 18 & 116.8 & 113.9 & -2.9 & -0.03 & \end{array}$

Panel C - Pregnancy Rate

$\begin{array}{lllllll}17 & 104.7 & 101.2 & -3.5 & -0.03 & 0.85(1.66) & 0.00(0.01) \\ 18 & 145.2 & 140.8 & -4.4 & -0.03 & & \end{array}$

${ }^{\#}$ See notes to Table 1.

${ }^{+}$Refers to the period from August 1, 1998 to July 31, 1999.

${ }^{* *}$ significant at $1 \%$; ${ }^{*}$ significant at $5 \%$ 
Table 3. Number of abortions to non-Texas resident teens that were performed in Texas, by year of conception, age at conception and state of residence ${ }^{\mathrm{a}}$

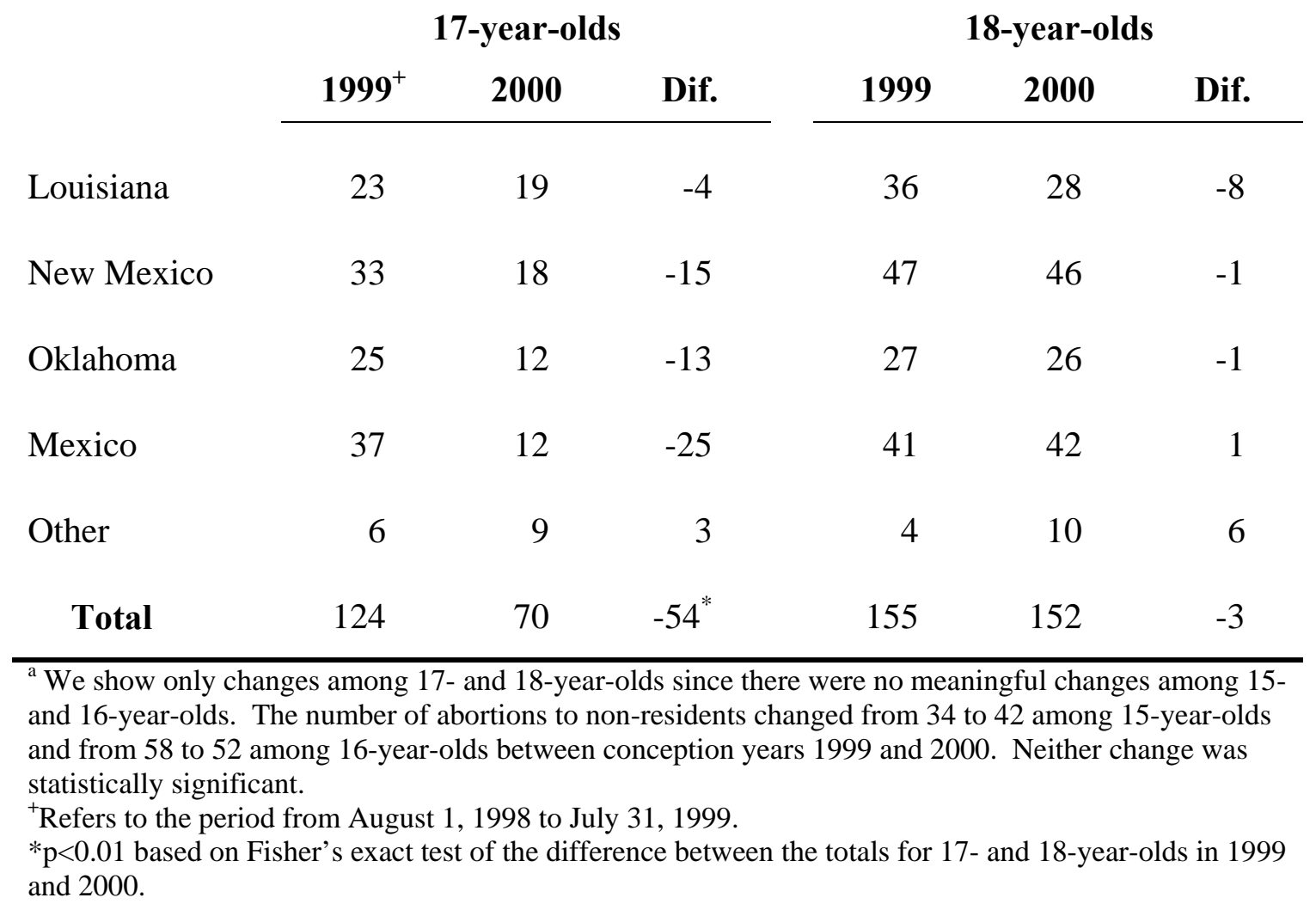


Table 4. Change in the probability that a pregnancy is aborted among 17-year-olds after the enactment of Texas' parental involvement law

\begin{tabular}{|c|c|c|c|}
\hline & $\begin{array}{c}\text { Model 1 } \\
1999-2000\end{array}$ & $\begin{array}{c}\text { Model } 2 \\
\text { 1999-2002 }\end{array}$ & $\begin{array}{c}\text { Model } 3 \\
\text { 1999-2002 }\end{array}$ \\
\hline & $(1)$ & $(2)$ & (3) \\
\hline Year 2000 x Age 17 & $-0.022(0.005)$ & $-0.022(0.005)$ & --- \\
\hline Year 2001 x Age 17 & --- & $-0.019(0.005)$ & --- \\
\hline Year 2002 x Age 17 & --- & $-0.016(0.005)$ & --- \\
\hline Whites: $\quad(2000-2002) \times 17$ & --- & --- & $-0.023(0.008)$ \\
\hline Blacks: $\quad(2000-2002) \times 17$ & --- & --- & $0.001(0.011)$ \\
\hline Hispanic: (2000-2002) x 17 & --- & --- & $-0.021(0.006)$ \\
\hline Blacks vs. whites & --- & --- & $0.025(0.013)$ \\
\hline Hispanics vs. whites & --- & --- & $0.002(0.010)$ \\
\hline $\begin{array}{l}\text { Wald-test of equality: } \\
\text { F( } 2,148659) \\
\text { Prob > F }\end{array}$ & & $\begin{array}{c}0.535 \\
{[0.586]}\end{array}$ & \\
\hline $\mathrm{N}$ & 75,646 & 148,685 & 148,685 \\
\hline
\end{tabular}

For all models, age is measured at the time of conception and the years refer to the year of conception. The omitted period is from August 1, 1998 to July 31, 1999. The omitted age group is those 18 at the time of conception. All estimates are adjusted for race/ethnicity, marital status, number of previous live births and terminations and region of residence.

${ }^{* *}$ significant at $1 \%$; ${ }^{*}$ significant at $5 \%$ 